\title{
Incidence and locations of deep venous thrombosis of the lower extremity following surgeries of tibial plateau fractures: a prospective cohort study
}

Junyong $\mathrm{Li}^{1,2,3,4,5+}$, Yanbin Zhu ${ }^{1,2,3,5+}$, Wei Chen ${ }^{1,2,3,5+}$, Kuo Zhao ${ }^{1,2,3,5}$, Junzhe Zhang ${ }^{1,2,3,5}$, Hongyu Meng ${ }^{1,2,3,5}$, Zhucheng Jin ${ }^{1,2,3,5}$, Dandan Ye $\mathrm{e}^{2,3,5}$ and Yingze Zhang ${ }^{1,2,3,5^{*}}$

\begin{abstract}
Objective: To investigate the incidence of deep venous thrombosis (DVT) of the lower extremities following surgeries of tibial plateau fractures.

Methods: Retrospective analysis of the prospectively collected data on patients undergoing surgeries of tibial plateau fractures between October 2014 and December 2018 was conducted. Duplex ultrasonography (DUS) was used to screen for postoperative DVT of the bilateral lower extremities. Data on demographics, comorbidities, injury, surgery, and laboratory biomarkers at admission were collected. Univariate analyses and multivariate logistic regression analyses were used to identify the independent risk factors associated with DVT.

Results: Among 987 patients included, 46 (4.7\%) had postoperative DVT, with incidence rate of 1.0\% for proximal and $3.7 \%$ for distal DVT. The average interval between operation and DVT was 8.3 days (median, 5.8 days), ranging from 2 to 42 days. DVT involved the injured extremity in 39 (84.8\%) patients, both the injured and uninjured extremity in 2 patients (4.3\%) and only the uninjured extremity in 5 patients (10.9\%). Five risk factors were identified to be associated with postoperative DVT, including age ( $\geq 41$ vs $<41$ years) (OR 3.08; 95\% Cl 1.43-6.61; $p=0.004$ ), anesthesia (general vs regional) (OR 2.08; 95\% Cl 1.12-3.85; $p=0.021$ ), hyponatremia (OR 2.21; 95\% Cl 1.21-4.06; $p=$ 0.010), prolonged surgical time (OR 1.04; $95 \% \mathrm{Cl} 1.01-1.07 ; p=0.017)$ and elevated D-dimer level $(\mathrm{OR} 2.79 ; 95 \% \mathrm{Cl}$ $1.34-4.83 ; p=0.004)$.

Conclusion: These epidemiologic data may be helpful in individualized assessment, risk stratification, and development of targeted prevention programs.
\end{abstract}

Keywords: Deep venous thrombosis, Surgical intervention, Tibial plateau fractures, Incidence, Risk factors

\footnotetext{
* Correspondence: suryzz@163.com

†Junyong Li, Yanbin Zhu and Wei Chen contributed equally to this work. 'Department of Orthopaedic Surgery, The 3rd Hospital of Hebei Medical University, Shijiazhuang 050051, Hebei, PR China

${ }^{2}$ Key Laboratory of Biomechanics of Hebei Province, Shijiazhuang 050051, Hebei, PR China

Full list of author information is available at the end of the article
}

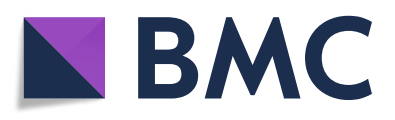

(- The Author(s). 2020 Open Access This article is licensed under a Creative Commons Attribution 4.0 International License, which permits use, sharing, adaptation, distribution and reproduction in any medium or format, as long as you give appropriate credit to the original author(s) and the source, provide a link to the Creative Commons licence, and indicate if changes were made. The images or other third party material in this article are included in the article's Creative Commons licence, unless indicated otherwise in a credit line to the material. If material is not included in the article's Creative Commons licence and your intended use is not permitted by statutory regulation or exceeds the permitted use, you will need to obtain permission directly from the copyright holder. To view a copy of this licence, visit http://creativecommons.org/licenses/by/4.0/. The Creative Commons Public Domain Dedication waiver (http://creativecommons.org/publicdomain/zero/1.0/) applies to the data made available in this article, unless otherwise stated in a credit line to the data. 


\section{Introduction}

As is well known, deep venous thrombosis (DVT) is a significant cause of morbidity, pulmonary embolism, and even mortality in all hospitalized patients, especially in the setting of trauma [1,2]. Tibial plateau fracture, a commonly seen knee injury, represents $1-2 \%$ of adult fractures and $32 \%$ of peri-knee fractures [3]. The postinjury hypercoagulation state, trauma stress, and systemic inflammatory response are early factors that contributed to the occurrence of DVT. Prolonged duration of extremity elevation and limited mobility, which is needed to allow the soft tissue envelop safe for surgical interventions aggravates the risk of DVT.

Extensive and deep understanding of the related risk factors is critical for prevention of occurrence of DVT, and it is of more clinical significance to distinguish between proximal and distal venous thrombosis, which allows more accurate diagnose and a more aggressive therapy for the proximal DVT. While DVT has been extensively studied in trauma, such as hip fracture, spinal fracture, pelvic and acetabular fracture, and multiple trauma [4-7], there is still lack of epidemiologic data on DVT following tibial plateau fracture. In most cases, the limited sample size in a single institution is powerless in statistical analyses. Besides, the confounding covariables from multi-aspects as trauma stress, patient comorbidities, or injury itself could affect the occurrence of DVT, and their respective role has not been definitely illuminated.

In this study, we used the prospectively collected data to evaluate the epidemiologic characteristics of postoperative DVT in tibial plateau fractures, including the incidence rate, the locations and of DVTs, and the associated risk factors.

\section{Methods}

The data used in this study were extracted from the database of Surgical Site Infection in Orthopaedic Surgery (SSIOS), in which data were prospectively collected on patients undergoing orthopaedic surgeries between October 1, 2014, and December 31, 2018, with the aim to identify surgical site infection. The SSIOS study was approved by the ethics committee of the $3^{\text {rd }}$ Hospital of Hebei Medical University (NO 2014-015-1), and got the informed consent of all the participants.

\section{Inclusion and exclusion criteria}

Patients included in this study must meet the following criteria: age of 18 years or older, undergoing surgery of tibial plateau fracture, and complete data available from medical records. Patients with pathological (metastatic) or old fracture (> 3 weeks from injury), concurrent fractures in other locations, with preoperative DVT during this hospitalization, with history of DVT or other thrombotic events, or with the current use of anticoagulants due to chronic comorbidities were excluded from this study.

In this study, all patients were preoperatively treated with an inflatable tourniquet at the thigh root of the affected limb with an inflated pressure of $280 \mathrm{mmHg}$, to reduce the study bias caused by the use of inflatable tourniquets.

During hospitalization stay, all patients received basic thromboprophylaxis, consisting of chemical (low molecular weight heparin (LMWH), 2500-4100 IU once daily, subcutaneous injection) and elevation of the injured lower extremity. Postoperative routine ultrasound examination of patients with deep vein thrombosis (DVT), according to guidelines for the treatment of deep vein thrombosis of the lower extremity, the treatment to be taken includes chemical drugs (low molecular heparin (LMWH), 2500-4100 IU twice daily, subcutaneous injection) and postoperative lower extremity elevation.

\section{Diagnosis of DVT}

DVT was diagnosed in accordance with the Guideline for the Diagnosis and Treatment of Deep Vein Thrombosis (3rd edition) proposed by the Chinese Medical Association [8]. During the postoperative period (the period between the first day after the operation and the period of discharge from the hospital), ultrasound examination of lower extremities was performed on the first day after the operation to determine whether deep vein thrombosis had occurred. After that, every 3 days after surgery routine duplex ultrasonography (DUS) scanning were performed in femoral common vein, superficial and deep femoral vein, popliteal vein, posterior and anterior tibial vein, and peroneal vein of bilateral lower extremities. The criteria of positivity were set as noncompressibility, lumen obstruction or filling defect, lack of respiratory variation in above knee segments, and inadequate flow augmentation to calf and foot compression maneuvers [9]. DVT localized in the popliteal vein or proximally was defined as proximal DVT, and those distal to popliteal vein were defined as distal DVT; if both distal and proximal DVT were present in one patient, he was classified in the proximal DVT group [10]. Superficial or intermuscular vein thrombosis (soleal or gastrocnemius vein thrombosis) were excluded, due to their relatively less clinical significance $[11,12]$.

\section{Data collection}

Data were from 5 aspects: demographics, comorbidities, injury, surgery, and laboratory biomarkers. The demographic data included age, gender, residence, body mass index (BMI), cigarette smoking, and alcohol consumption. The comorbidities included hypertension, diabetes, chronic heart disease, chronic liver disease, history of any surgery, and allergies to any medications, all of 
which were self-reported by patients. Injury-related data included injury mechanism, open or closed fracture, fracture classification based on Schatzker classification system. The surgery-realted data included preoperative interval since fracture, fracture reduction mode, American Society of Anesthesiologists (ASA) classification, bone graft, surgical duration, day or night surgery, and perioeprative blood transfusion. The BMI $\left(\mathrm{kg} / \mathrm{m}^{2}\right)$ was divided using the criteria recommended by the Chinese working group on obesity: normal (18.5-23.9), underweight $(<18.5)$, overweight (24.0-27.9), and obesity ( $\geq 28.0$ ) [13]. Low-energy injury was defined as an injury caused by a fall from a standing height, while fall from a height more than $2 \mathrm{~m}$ or motor accidents as high-energy injury.

The biomarkers at admission included total protein (TP) level, albumin (ALB) level, globulin (GLOB), ALB/GLOB, alanine transaminase (ALT), aspartate transaminase (AST), alkaline phosphatase (ALP), lactate dehydrogenase (LDH), uric acid (UA), fasting blood glucose (FBG) level, total bilirubin (TBIL), direct bilirubin (DBIL), indirect bilirubin (IBIL), red blood cell (RBC) count, white blood cell (WBC) count, neutrophile (NEUT) count, lymphocyte (LYM) count, monocyte (MON), hemoglobin (HGB) level, hematocrit (HCT), platelet (PLT), red blood cell distribution width (RDW), platelet distribution width (PDW), mean erythrocyte volume (MCV), mean corpuscular hemoglobin $(\mathrm{MCH})$, mean corpuscular hemoglobin concentration (MCHC), total cholesterol (TC) level, triglyceride (TG) level, low-density lipoprotein (LDL-C) level, high-density lipoprotein (HDL-C) level, very low-density lipoprotein (VLDL) level, sodium concentration $(\mathrm{Na}+)$, chloride concentration (Cl-), D-dimer level, and osmotic pressure (OSM).

\section{Statistical analysis}

Continuous variables were expressed by mean and standard deviation (SD) and were evaluated by Student's $t$ test or Mann-Whitney $U$ test, as appropriate. The categorical data were expressed as number and percentage (\%) and were evaluated by chi-squared or Fisher's exact test, as appropriate.

Giving the association of D-dimer and advancing age in DVT formation, receiver operating characteristic (ROC) was constructed to determine the optimal cutoff value, above which the risk of DVT was significantly increased. The significance of the ROC curve was tested using the area under the curve (AUC) analysis, with $p<0.05$ as significance level.

Variables tested as approximately significant in the univariate analyses were entered into the multivariate logistics regression model. Stepwise backward elimination method was used to exclude varaible one by one. Variables with $p<0.10$ were retained in the final model, and the correlation strength is indicated by odd ratio
(OR) and $95 \%$ confidence interval $(95 \% \mathrm{CI})$. The significance level was set as $p<0.05$. Hosmer-lemeshow (H-L) test was used to evaluate the fitting degree of the final model, and $p>0.05$ represented the acceptable result. SPSS23.0 was used to perform all the tests (IBM, Armonk, New York, USA).

\section{Results}

Among 987 patients included, 603 (61.1\%) were males and $384(38.9 \%)$ were females, with 45.2 years in average (Sd, 13.9; range, 18-82; median, 45.0). There were 638 $(64.6 \%)$ fractures that were caused by high-energy trauma, and $49(5.0 \%)$ were open fractures. Based on Schatzker classification system, 700 (70.9\%) were classified as types I-IV, and 287 (29.1\%) as types V-VI.

Postoperatively, 46 patients were diagnosed to have DVT, indicating the incidence of $4.7 \%$. No thrombosis was found in anterior tibial vein. At the other 6 veins, there were 78 clots, representing an average of 1.70 (range, 1 to 5) for each patient. DVT involved the injured extremity in 39 patients, both the injured and uninjured extremity in $2(4.3 \%)$ patient and only the uninjured extremity in $5(10.9 \%)$ patients. DVT involved proximal vein in 10 patients and distal vein in 36 patients, with incidence rate of $1.0 \%$ and $3.7 \%$, respectively. The details were 1 in femoral common vein, 3 in superficial and 1 in deep femoral vein, 7 in popliteal vein, 29 in posterior tibial vein, and 37 in peroneal vein. The average interval between operation and DVT was 8.3 days (median, 5.8 days), ranging from 2 to 42 days. Compared to those without postoperative DVT, patients with a postoperative DVT had a significantly longer total hospitalization stay $(29.8 \pm 26.8$ vs $18.6 \pm 22.2, p=0.001)$.

The optimal cutoff value for D-dimer was identified at $1.75 \mathrm{mg} / \mathrm{L}$, with a sensitivity of 0.860 and specificity of 0.174 ( $p=0.021$; AUC, $0.604 ; 95 \%$ CI, 0.517 to 0.692$)$ (Fig. 1$)$. The optimal cutoff value for age was 41 years, with a sensitivity of 0.804 and specificity of $0.412(p=0.018$; AUC, 0.603 ; 95\%CI, 0.525 to 0.681) (Fig. 2).

Table 1 presented the univariate analyses. DVT and non-DVT group differed in living area, anesthesia pattern, age in continuous or categorical variable, surgical duration, LDH, TP, HBDH, $\mathrm{Na}+$ and $\mathrm{K}+$ concentration, HGB level, D-dimer ( $\geq 1.75 \mathrm{mg} / \mathrm{L}$ ), and OSM.

In the multivariate model, the abovementioned 13 variables, together with open fracture $(p=0.059)$, alcohol consumption $(p=0.050)$, ASA $(p=0.085)$, ALB $(p=0.090)$, $\operatorname{HCRP}(p=0.051), \operatorname{WBC}(p=0.071), \mathrm{HCT}(p=0.072)$, Ddimer $>0.5 \mathrm{mg} / \mathrm{L}(p=0.072)$, and PLT $(p=0.068)$ were included. At the final model, five risk factors were identified as independent factors associated with DVT, including age ( $\geq 41$ vs $<41$ years), general anesthesia (vs regional), hyponatremia, prolonged surgical duration, and D-dimer $\geq$ $1.75 \mathrm{mg} / \mathrm{L}$ (Table 2). The $\mathrm{H}-\mathrm{L}$ test demonstrated the 


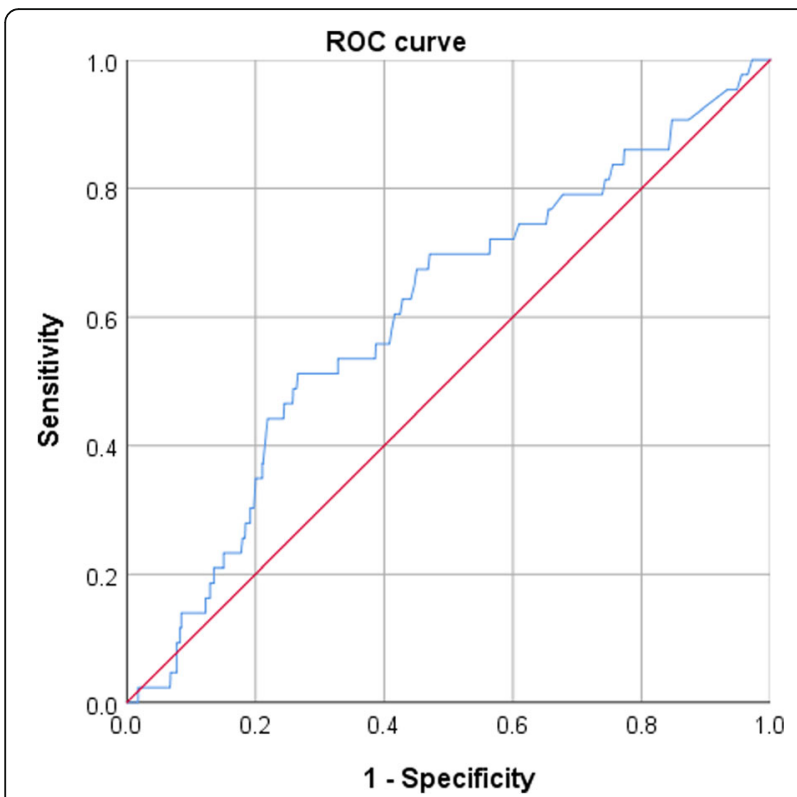

Fig. 1 The inflection point of the ROC curve corresponded to Ddimer level above $1.75 \mathrm{mg} / \mathrm{L}$ ( $p=0.021$, AUC, $0.604 ; 95 \% \mathrm{Cl}, 0.517$ to 0.692 ; sensitivity $=0.860$, specificity of 0.174 )

good fitness of the final model $\left(X^{2}=10.406, p=0.109\right.$; Nagelkerke $R^{2}=0.068$ ).

\section{Discussion}

In the present study, we used a large-sample prospective cohort to address the epidemiologic characteristics of DVT following surgeries of tibial plateau fractures. We found the overall incidence of DVT following tibial plateau fracture was $4.7 \%$, with $1.0 \%$ for proximal and 3.7\% for distal DVT. Patients with a postoperative DVT were associated with a significantly prolonged total hospitalization stay by 11.2 days. Five risk factors were identified to be independently associated with postoperative DVT, including age ( $\geq 41$ vs $<41$ years), general anesthesia, hyponatremia, prolonged surgical time, and elevated D-dimer level $(\geq 1.75 \mathrm{mg} / \mathrm{L})$.

Several studies have reported the DVT following surgeries of lower extremity fractures, with greatly variable incidence rates [10, 14-17], but few studies were specified at tibial plateau fractures, especially the postoperative DVT. In a cohort of specific isolated lower extremity fractures, Wang et al. [16] reported the incidence rate of postoperative DVT was $45.4 \%$ in 176 tibial plateau fractures, and all the patients received thromboprophylaxis consisting of low molecular weight heparin (LMWH) and pneumatic compression with foot pump before and after surgery. Goel et al. [18] conducted a prospective randomized trial to compare the incidence of DVT following fractures below the knee and found the lower rate of DVT in group of patients receiving LMWH than that of those

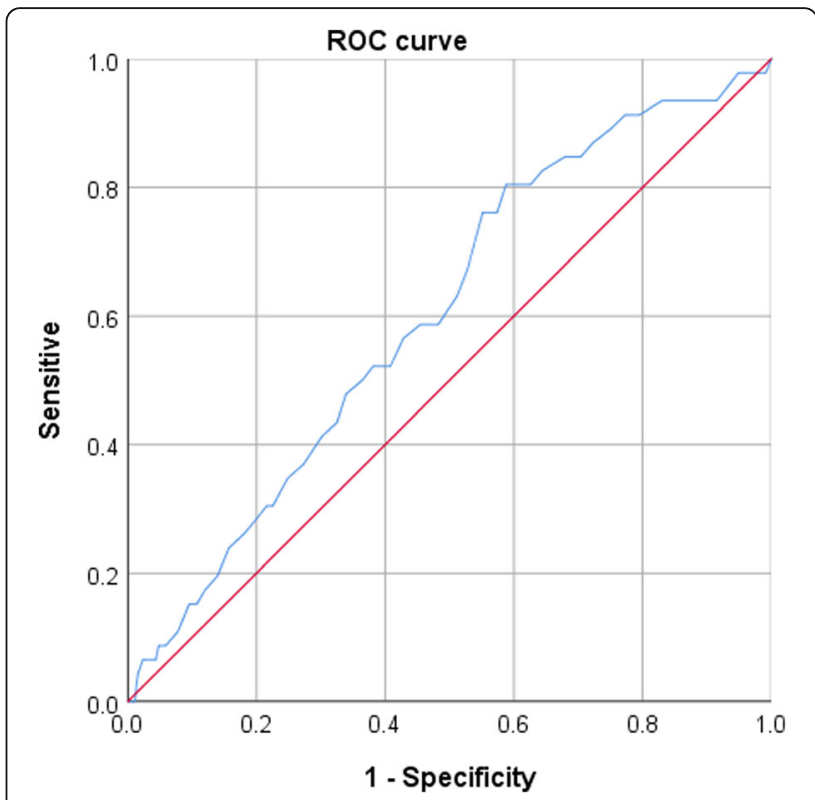

Fig. 2 The inflection point of the ROC curve corresponded to the age above 41 years ( $p=0.018$; AUC, $0.603 ; 95 \% \mathrm{Cl}, 0.525$ to 0.681 ; sensitivity $=0.804$, specificity of 0.412 )

receiving placebo ( $8.7 \%$ vs $12.6 \%)$. In this study, we found a lower rate of DVT, that was $4.7 \%$, relatively lower than the previous reports. The following may be used to account for such difference. Firstly, intermuscular vein thrombosis was excluded in this study due to its less clinical significance, whereas the studies both by Wang et al. [16] and Goel et al. did not distinguish among them. Secondly, we only investigated the in-hospital rate of DVT, so the follow-up was relatively shorter, and our data also showed that $27 \%$ of DVTs were detected 2 weeks after surgery. In the study by Goel et al. [18], the follow-up was lasted until 12 weeks, 7fold as long as ours (average, 12.6 days). Thirdly, patients with preoperative DVTs were also excluded, and for these patients, their risk of postoperative DVT demonstrated to be higher than those without a preoperative DVT [19]. Fourthly, patients in this study were younger (mean, 45.6 years) than that (mean, 62.8 years) of Wang et al's study [10], and age has always been a risk factor for DVT [17]. Additionally, the ethnicity or race should also be the contributors, and in Asian population, the risk of DVT was lower [20, 21].

Proximal DVT, a well-known increased risk for pulmonary embolism, generally necessitate further management. In this study, it was found to be $1.0 \%$ following surgeries of tibial plateau. In comparison, Goel et al. [18] found no proximal DVT either in the experimental or placebo group; but Wang et al. [10] found a rate of $4.5 \%$ of proximal DVT following surgeries of tibial plateau fractures, and we inferred advanced age was still an important influential factor. Some authors suggested the 
Table 1 Univariate analyses of risk factors associated with DVT following surgeries of tibial plateau fracture

\begin{tabular}{|c|c|c|c|}
\hline Variables & $\begin{array}{l}\text { Number (\%) of } \\
\text { DVT }(n=46)\end{array}$ & $\begin{array}{l}\text { Number }(\%) \text { of } \\
\text { non-DVT }(n=941)\end{array}$ & $P$ \\
\hline Gender (male) & $30(65.2)$ & $573(60.9)$ & 0.557 \\
\hline Age (years) & $49.8 \pm 13.1$ & $45.0 \pm 13.9$ & 0.020 \\
\hline $18-40$ & $9(19.6)$ & $388(41.2)$ & 0.003 \\
\hline$\geq 41$ & $37(80.4)$ & $553(58.8)$ & \\
\hline Living area & & & $<0.001$ \\
\hline Rural & $27(58.7)$ & $577(61.2)$ & \\
\hline Urban & 19(39.1) & $365(38.8)$ & \\
\hline BMI $\left(\mathrm{kg} / \mathrm{m}^{2}\right)$ & & & 0.934 \\
\hline $18.5-23.9$ & $14(30.4)$ & $306(32.5)$ & \\
\hline$<18.5$ & $1(2.2)$ & $18(1.9)$ & \\
\hline $24-27.9$ & $20(43.5)$ & $389(41.3)$ & \\
\hline$\geq 28.0$ & $11(23.9)$ & $228(24.3)$ & \\
\hline Diabetes mellitus & $5(10.9)$ & $126(13.4)$ & 0.623 \\
\hline Hypertension & $7(15.2)$ & $160(17.0)$ & 0.752 \\
\hline Cerebrovascular disease & 0 & $12(1.3)$ & 0.441 \\
\hline Chronic heart disease & $2(4.3)$ & $40(4.3)$ & 0.975 \\
\hline Chronic liver disease & $2(4.3)$ & $45(4.8)$ & 0.893 \\
\hline History of any surgery & $7(15.2)$ & 109 (11.6) & 0.455 \\
\hline Allergy to any medications & $5(10.9)$ & $116(12.3)$ & 0.768 \\
\hline Current smoking & $6(13.0)$ & $123(13.1)$ & 0.996 \\
\hline Alcohol consumption & $8(17.4)$ & $83(8.8)$ & 0.050 \\
\hline Preoperative duration (day) & $7.1 \pm 7.8$ & $6.8 \pm 6.7$ & 0.781 \\
\hline Total hospital stay & $29.8 \pm 26.8$ & $18.6 \pm 22.2$ & 0.001 \\
\hline Mechanism (high-energy) & $30(65.2)$ & $608(64.6)$ & 0.933 \\
\hline Open fracture & $5(10.9)$ & $44(4.7)$ & 0.059 \\
\hline ASA class & & & 0.085 \\
\hline I & $4(8.7)$ & $134(14.2)$ & \\
\hline$\|$ & $31(67.4)$ & $684(72.7)$ & \\
\hline III or above & $11(23.9)$ & $123(13.1)$ & \\
\hline Fracture type (Schartzker) & & & 0.397 \\
\hline I-IV & $31(67.4)$ & $669(71.1)$ & \\
\hline V-VI & $15(32.6)$ & $272(28.9)$ & \\
\hline Anesthesia (general) & 28(60.9) & $369(39.2)$ & 0.003 \\
\hline Open reduction (vs closed) & $34(93.5)$ & $96(91.2)$ & 0.589 \\
\hline Bone grafting (yes) & 13(28.3) & 186(19.8) & 0.161 \\
\hline Surgical duration & $182.4 \pm 77.0$ & $148.6 \pm 82.0$ & 0.012 \\
\hline Perioperative blood transfusion & $7(15.2)$ & $97(10.3)$ & 0.290 \\
\hline Operation timing & & & 0.942 \\
\hline Day & 45(97.8) & $922(98.0)$ & \\
\hline Night & $1(2.2)$ & $19(2.0)$ & \\
\hline $\mathrm{TP}(<60 \mathrm{~g} / \mathrm{L})$ & $19(41.3)$ & $242(25.7)$ & 0.019 \\
\hline ALB (< $35 \mathrm{~g} / \mathrm{L})$ & $14(30.4)$ & $189(20.1)$ & 0.090 \\
\hline$A / G$ & & & 0.111 \\
\hline
\end{tabular}


Table 1 Univariate analyses of risk factors associated with DVT following surgeries of tibial plateau fracture (Continued)

\begin{tabular}{|c|c|c|c|}
\hline Variables & $\begin{array}{l}\text { Number (\%) of } \\
\text { DVT }(n=46)\end{array}$ & $\begin{array}{l}\text { Number }(\%) \text { of } \\
\text { non-DVT }(n=941)\end{array}$ & $P$ \\
\hline $1.2-2.4$ & $38(82.6)$ & $835(89.8)$ & \\
\hline$<1.2$ & $7(15.2)$ & $66(7.0)$ & \\
\hline$>2.4$ & $1(2.2)$ & $30(3.2)$ & \\
\hline ALT $(>40 \mathrm{U} / \mathrm{L})$ & $7(15.2)$ & 173(18.4) & 0.587 \\
\hline AST (> $35 \mathrm{U} / \mathrm{L})$ & $6(13.0)$ & $128(13.6)$ & 0.914 \\
\hline TBIL (> 21 umol/L) & $4(8.7)$ & $78(8.3)$ & 0.922 \\
\hline DBIL (> 6 umol/L) & $17(37.0)$ & $257(27.3)$ & 0.154 \\
\hline IBIL (> 14 umol/L) & $8(17.4)$ & $142(15.1)$ & 0.671 \\
\hline $\operatorname{ALP}(>100)$ & $3(6.5)$ & $38(4.0)$ & 0.410 \\
\hline HCRP (> $8 \mathrm{mg} / \mathrm{L})$ & $37(80.4)$ & $627(66.6)$ & 0.051 \\
\hline $\mathrm{LDH}(>250 \mathrm{U} / \mathrm{L})$ & 16(34.8) & 198(21.0) & 0.027 \\
\hline HBDH (> 182 U/L) & 13(28.3) & 153(16.3) & 0.034 \\
\hline $\mathrm{TC}(>5.2 \mathrm{mmol} / \mathrm{L})$ & $3(6.5)$ & $118(12.5)$ & 0.224 \\
\hline TG (> $1.7 \mathrm{mmol} / \mathrm{L})$ & $4(8.7)$ & 163(17.3) & 0.128 \\
\hline $\mathrm{HDL}-\mathrm{C}(<1.1 \mathrm{mmol} / \mathrm{L})$ & $23(50.0)$ & $365(38.8)$ & 0.128 \\
\hline LDL-C (> $3.37 \mathrm{mmol} / \mathrm{L})$ & $6(13.0)$ & 129(13.7) & 0.898 \\
\hline VLDL (> $0.78 \mathrm{mmol} / \mathrm{L})$ & $4(8.7)$ & 158(16.8) & 0.148 \\
\hline $\mathrm{Na}+(<135 \mathrm{mmol} / \mathrm{L})$ & $23(50.0)$ & 263(27.9) & 0.001 \\
\hline $\mathrm{K}+(\mathrm{mmol} / \mathrm{L})$ & & & 0.001 \\
\hline $3.5-5.5$ & $40(87.0)$ & 874(92.9) & \\
\hline$<3.5$ & $3(6.5)$ & $60(6.4)$ & \\
\hline$>5.5$ & $3(6.5)$ & $7(0.7)$ & \\
\hline UA (> upper limit) & $1(2.2)$ & $77(8.2)$ & 0.140 \\
\hline WBC $\left(>10 \times 10^{9} / L\right)$ & $20(43.5)$ & $290(30.8)$ & 0.071 \\
\hline $\operatorname{LYM}\left(<1.1 \times 10^{9} / \mathrm{L}\right)$ & $17(37.0)$ & $266(28.3)$ & 0.203 \\
\hline MON $\left(>0.6 \times 10^{9} / \mathrm{L}\right)$ & $30(65.2)$ & $562(59.7)$ & 0.458 \\
\hline $\mathrm{RBC}<$ lower limit & $21(45.7)$ & $367(39.0)$ & 0.367 \\
\hline HGB < lower limit & $31(67.4)$ & 495(52.6) & 0.049 \\
\hline HCT < lower limit & $34(73.9)$ & $571(60.7)$ & 0.072 \\
\hline $\mathrm{MCV}(\mathrm{fL})$ & & & 0.830 \\
\hline $82-100$ & $43(93.5)$ & $875(93.0)$ & \\
\hline$<82$ & $1(2.2)$ & $34(3.6)$ & \\
\hline$>100$ & $2(4.3)$ & $32(3.4)$ & \\
\hline $\mathrm{MCH}(\mathrm{pg})$ & & & 0.585 \\
\hline $27-34$ & $42(91.3)$ & $861(91.5)$ & \\
\hline$<27$ & $3(6.5)$ & $39(4.1)$ & \\
\hline$>34$ & $1(2.2)$ & $41(4.4)$ & \\
\hline $\operatorname{MCHC}(<316 \mathrm{~g} / \mathrm{L})$ & $3(6.5)$ & $26(2.8)$ & 0.134 \\
\hline PDW (\%) & & & 0.197 \\
\hline $12-18.1$ & $42(91.3)$ & $829(88.1)$ & \\
\hline$<12$ & $2(4.3)$ & $96(10.2)$ & \\
\hline$>18.1$ & $2(4.3)$ & $16(1.7)$ & \\
\hline D-dimer (> $0.50 \mathrm{mg} / \mathrm{L})$ & $32(69.6)$ & $528(56.1)$ & 0.072 \\
\hline
\end{tabular}


Table 1 Univariate analyses of risk factors associated with DVT following surgeries of tibial plateau fracture (Continued)

\begin{tabular}{|c|c|c|c|}
\hline Variables & $\begin{array}{l}\text { Number }(\%) \text { of } \\
\text { DVT }(n=46)\end{array}$ & $\begin{array}{l}\text { Number }(\%) \text { of } \\
\text { non-DVT }(n=941)\end{array}$ & $P$ \\
\hline D-dimer (> $1.76 \mathrm{mg} / \mathrm{L})$ & $22(47.8)$ & $231(24.5)$ & $<0.001$ \\
\hline OSM $<260 \mathrm{mOsm} / \mathrm{L}$ & $10(21.7)$ & $85(9.0)$ & 0.004 \\
\hline $\mathrm{PLT}>300 \times 10^{9} / \mathrm{L}$ & $15(32.6)$ & $200(21.3)$ & 0.068 \\
\hline NEUT $>6.3 \times 10^{9} / \mathrm{L}$ & $27(58.7)$ & $441(46.9)$ & 0.117 \\
\hline FBG $(>6.1 \mathrm{mmol} / \mathrm{L})$ & $16(34.8)$ & $318(33.8)$ & 0.890 \\
\hline RDW (> 16.5\%) & $5(5.1)$ & $54(3.8)$ & 0.506 \\
\hline
\end{tabular}

$B M I$ body mass index; $A S A$ American Society of Anesthesiologists; $R B C$ red blood cell, reference range: females, 3.5-5.0 $\times 10^{12} / \mathrm{L} ; \mathrm{males}, 4.0-5.5 \times 10^{12} / \mathrm{L}$. $H G B$ hemoglobin, reference range: females, $110-150 \mathrm{~g} / \mathrm{L}$; males, $120-160 \mathrm{~g} / \mathrm{L} ;$ FBG fasting blood glucose; HCT hematocrit, $40-50 \%$; WBC white blood cell; NEUT neutrophile; $L Y M$ lymphocyte; PLT platelet, $100-300 \times 10^{9} / \mathrm{L} ;$ TP total protein; $A L B$ albumin; RDW red cell distribution width; PDW platelet distribution width; TC total cholesterol; TG triglyceride; $L D L-C$ low-density lipoprotein; $H D L-C$ high-density lipoprotein; VLDL very low-density lipoprotein

risk of proximal DVT was related to the fracture sites that were higher in fractures more proximal to the hip [10, 22, 23]. Anyhow, we did not ignore the role of distal DV, and in some study, it demonstrated to present a similar risk of pulmonary embolism as proximal DVT [24]. We also observed the relatively few incident DVTs in the bilateral (rate, 5.1\%) or even only in uninjured extremity (rate, $2.0 \%)$, which was consistent with the previous finding [18, 22]. Obviously, bilateral examination was worthwhile for potential DVTs in the uninjured extremity.

Age, either in continuous form or in categorical form, was identified to be independently associated with DVT in studies $[18,25]$ or was listed an important factor in guideline [26]. Of interest was the cutoff value of age set as 40 years more or less in these studies, consistent with our finding. An important reason might be the fact that patients at age of 40-44 years were more likely the sustainers of high-energy trauma and the resultant complex fractures, e.g., Schatzker V-VI fractures [27], which was also associated with DVT [18]. We used ROC curve to determine the optimal cutoff value of age ( 41 years) with a relatively high sensitivity of 0.804 , suggesting the applicability of age in initial screening for DVT.

Although previous studies demonstrated that delay to surgical intervention was associated with risk of DVT $[10,28]$, we were unable to identify the association in this study. According to Goel et al. [18], the reduced time of immobilization before surgery reduce the risk of DVT, and in their study, they found a rate of $8.7 \%$ of DVT following surgery of lower extremity fracture within $48 \mathrm{~h}$ of fracture; however, this contrasted with another finding of $3.9 \%$ rate of DVT in patients treated with plaster immobilization who received thromboprophylaxis [29]. In a previous study, Wilson et al. [30] suggested that the blood coagulation was highest in 3-7 days after fracture, which could partly explain why more authors tend to operate within $48 \mathrm{~h}$ after fracture for reduction of DVT.

D-dimer level in plasma reflects the secondary increased fibrinolytic activity and the hypercoagulability, which is a well-established sensitive marker of thrombotic events. In clinical practice, $0.5 \mathrm{mg} / \mathrm{L}$ was generally used as a cutoff value, but it could not exhibit a satisfactory differentiation in diagnosis of DVT in this study. Given its clinical importance, we used ROC to determine that the optimal cutoff value of $\mathrm{D}$-dimer was $1.75 \mathrm{mg} / \mathrm{L}$, and above which was identified to be independently associated with DVT. The high sensitivity of 0.860 showed its usefulness in screening for suspected thrombotic events, and this figure was in range of the reports, from 76 to $93 \%$ based on different settings [31-33]. But the low specificity remained an issue, being only 0.174 in this study. Similar as ours, Zhang et al. [34] also re-defined the cutoff of D-dimer level as preoperative $4.01 \mathrm{mg} / \mathrm{L}$ and postoperative $5.03 \mathrm{mg} / \mathrm{L}$ in traumatic fractures, and they found the lower sensitivity (preoperative, 0.713; postoperative, 0.639) and higher specificity (preoperative, 0.448 ; postoperative, 0.705 ) in diagnosis of perioperative DVT. It is pity that we were unable to obtain data on postoperative D-dimer level, and their role required to be determined in the future.

Table 2 Multivariate analysis of factors associated with DVT following surgeries of tibial plateau fractures

\begin{tabular}{lllll}
\hline Variables & OR & $\mathbf{9 5 \% C l}$ (lower limit) & $\mathbf{9 5 \% C l ~ ( u p p e r ~ l i m i t ) ~}$ & $\mathbf{P}$ \\
\hline Age $(\geq 41$ vs $<41$ years) & 3.08 & 1.43 & 6.61 & 0.004 \\
Anesthesia (general vs regional) & 2.08 & 1.12 & 3.85 & 0.021 \\
Hyponatremia (< $135 \mathrm{mmol} / \mathrm{L})$ & 2.21 & 1.21 & 4.06 & 0.010 \\
Surgical time (increase of every 15 min) & 1.04 & 1.01 & 1.07 & 0.017 \\
D-dimer $(\geq 1.75 \mathrm{mg} / \mathrm{L})$ & 2.79 & 1.34 & 4.83 & 0.004 \\
\hline
\end{tabular}


In addition, we also identified the hyponatremia, general anesthesia, and prolonged surgical duration were independently associated with the formation of postoperative DVT. Hyponatremia is common in trauma events and was found to involve $29.0 \%$ of our patients. It is reported that both hyper- or hyponatremia were associated with the increased risk of venous thromboembolism or even mortality [35]. Therefore, correction of preoperative saline imbalance is of importance in reduction or prevention of postoperative DVT. Prolonged surgical duration by $15 \mathrm{~min}$ was identified to be associated with $4 \%$ increased risk of DVT, consistent with the Abelseth et al.'s [22] finding that prolonged time $\geq 105 \mathrm{~min}$ was associated with thromboembolic disease in lower extremity fracture distal to the hip. But this factor should be regarded dialectically. In more cases, prolonged surgical duration was a marker of difficulty in management of more complex fracture, soft tissue injury or inexperience of surgeons. On the other hand, some external factors such as operation night, surgeon fatigue, cooperation with assistants, and obese patient also affect the surgical process. General anesthesia as an important factor for DVT was extensively discussed in trauma [36] or arthroplasty [37, 38]; however, it was firstly reported as specified at tibial plateau fracture. The might be explained by the fact that regional anesthesia allowed early mobility and improved the postoperative functional outcome and pain relief after surgery [39].

Although most of these factors might not be easily modifiable, they did aid in counseling by patients about their risk of postoperative DVT. We suggest the use of regional anesthesia as much as possible when both local and general anesthesia were indicated. In addition, positive correction of preoperative imbalance of sodium ions and optimized surgical scheme, improved surgical skills, and cooperation with operation room staff to reduce surgical duration were feasible in prevention or reduction of postoperative DVT formation.

There were several limitations in this study. Firstly, as other multivariate analyses, we could not include all the potential factors that affect the occurrence of DVT, such as duration of immolization of the injured extremity before and after operation [11]. Secondly, for some uncommon medical conditions or comorbidities such as chronic nephrosis or long-term use of glucocorticoid, it is almost impossible to confirm their association with DVT. Thirdly, in this study, we used various types of LMWH, single dose (range, 2500-4100 IU), and usage days in variety, but we could not evaluate their respective effect in DVT formation. Fourth, we identified the association rather than the causation between variables and DVT; therefore, these results should be interpreted with caution.

\section{Conclusion}

In summary, the incidence of DVT following surgeries of tibial plateau fracture was $4.7 \%$, with $1.0 \%$ for proximal and $3.7 \%$ for distal DVT. Five risk factors were identified to be independently associated with postoperative DVT, including age ( $\geq 41$ vs $<41$ years), general anesthesia, hyponatremia, prolonged surgical time, and elevated D-dimer level $(\geq 1.75 \mathrm{mg} / \mathrm{L})$. Although most of them might not be easily modifiable, they were conducive to the individualized assessment, risk stratification, and development of targeted prevention programs.

\section{Abbreviations}

DVT: Deep venous thrombosis; DUS: Duplex ultrasonography; SSIOS: Surgical Site Infection in Orthopaedic Surgery; LMWH: Low molecular weight heparin

\section{Acknowledgements}

We appreciate the contribution of all patients, their families, the investigators, and the medical staff. We are grateful to all authors.

\section{Authors' contributions}

Yingze Zhang conceived the idea for the study; Yanbin Zhu and Wei Chen designed the study. Kuo Zhao, Junzhe Zhang, Hongyu Meng, Junyong Li, Zhucheng Jin, and Dandan Ye collected the relevant data and followed-up the patients. Junyong Li and Dandan Ye prepared the figures and tables. Wei Chen performed the statistical analyses. All the authors interpreted the data and contributed to the preparation of the manuscript. Junyong Li, Yanbin Zhu, and Wei Chen contributed equally to this manuscript. The authors read and approved the final manuscript.

\section{Funding}

There is no funding received.

\section{Availability of data and materials}

The data and materials contributing to this article may be made available upon request by sending an e-mail to the first author.

\section{Ethics approval and consent to participate}

The ethics committee of our hospital approved the SSIOS (NO 2014-015-1), and all the participants had written the informed consent.

\section{Consent for publication}

Consent to publish was obtained from the patient detailed in this study.

\section{Competing interests}

The authors declare no conflict of interests.

\section{Author details}

${ }^{1}$ Department of Orthopaedic Surgery, The 3rd Hospital of Hebei Medical University, Shijiazhuang 050051, Hebei, PR China. ${ }^{2}$ Key Laboratory of Biomechanics of Hebei Province, Shijiazhuang 050051, Hebei, PR China. ${ }^{3}$ Orthopaedic Institution of Hebei Province, Shijiazhuang 050051, Hebei, PR China. ${ }^{4}$ The Second Hospital of Shijiazhuang City, Shijiazhuang 050051, Hebei, PR China. ${ }^{5} \mathrm{NHC}$ Key Laboratory of Intelligent Orthopeadic Equipment, Hebei 050051 Shijiazhuang, People's Republic of China.

Received: 26 September 2020 Accepted: 30 November 2020 Published online: 14 December 2020

\section{References}

1. Lapidus LJ, Rosfors S, Ponzer S, Levander C, Elvin A, Lärfars G, de Bri E. Prolonged thromboprophylaxis with dalteparin after surgical treatment of achilles tendon rupture: a randomized, placebo-controlled study. J Orthopaedic Trauma. 21(1):52-7.

2. J Lapidus L, Ponzer S, Elvin A, Levander C, Larfars G, Rosfors S, De Bri E: Prolonged thromboprophylaxis with Dalteparin during immobilization after ankle fracture surgery: a randomized placebo-controlled, double-blind study. Acta Orthopaedica, 78(4):528-535. 
3. Zhang Y. Clinical epidemiology of orthopedic trauma: thieme; 2012.

4. Durand WM, Goodman AD, Johnson JP, Daniels AH. Assessment of 30-day mortality and complication rates associated with extended deep vein thrombosis prophylaxis following hip fracture surgery; 2018.

5. Jiang X, Wu B, Kang J. Analysis of risk factors for lower-limb deep venous thrombosis in old patients after knee arthroplasty. Chin Med J (Engl). 2015; 128(10):1358.

6. Masuda M, Ueta T. Shiba K. Iwamoto Y: D-dimer screening for deep venous thrombosis in traumatic cervical spinal injuries. 2015;15(11):2338-44.

7. $T N, S Y L, K O, A$ K $, T K, Y D, E O, M K$ : Incidence of venous thromboembolism in pelvic and acetabular fractures in the Japanese population. Journal of orthopaedic science: official journal of the Japanese Orthopaedic Association 2012, 17(3):233-238

8. Association VsgoCm. Guidelines for the diagnosis and treatment of deep vein thrombosis (3rd edition). Chin J Gen Surg. 2017;32(9):807-12.

9. Cogo A, Lensing AWA, Koopman MMW, Piovella F, Siragusa S, Wells PS, Villalta S, Büller HR, Turpie AGG, Prandoni P: Compression ultrasonography for diagnostic management of patients with clinically suspected deep vein thrombosis: prospective cohort study. 1998, 316(7124):17-20.

10. Wang H, Kandemir U, Liu P, Zhang H, Wang P-F, Zhang B-F, Shang K, Fu YH, Ke C, Zhuang Y. Perioperative incidence and locations of deep vein thrombosis following specific isolated lower extremity fractures. Injury. 2018; S0020138318302614

11. Solis G, Saxby T. Incidence of DVT following surgery of the foot and ankle. Foot \& Ankle International. 2002;23(5):411-4.

12. Elfandi A, Anghel S, Sales C. Current management of isolated soleal and gastrocnemius vein thrombosis. J Vasc Surg Venous Lymphat Disord. 3(3):341-4.

13. Zhu Y, Liu S, Zhang X, Chen W, Zhang Y. Incidence and risks for surgical site infection after adult tibial plateau fractures treated by ORIF: a prospective multicentre study: SSI after tibial plateau fracture. International Wound Journal. 2017;14:6.

14. Adams RC, Hamrick M, Berenguer C, Senkowski C, Ochsner MG. Four years of an aggressive prophylaxis and screening protocol for venous thromboembolism in a large trauma population. Journal of Trauma \& Acute Care Surgery. 2008;65(2):300-6 discussion 306-308.

15. Wang H, Kandemir U, Liu P, Zhang H, Wang P-F, Zhang B-F, Shang K, Fu Y$H$, Ke C, Zhuang Y: Perioperative incidence and locations of deep vein thrombosis following specific isolated lower extremity fractures. Injury: S0020138318302614.

16. M WJZCWJW. Risk factors of deep venous thrombosis in lower extremity of tibial plateau fracture. Chin j bone joints. 2015;2:86-90.

17. Decker $\mathrm{S}$, Weaver MJ. Deep venous thrombosis following different isolated lower extremity fractures: what is known about prevalences, locations, risk factors and prophylaxis? Eur J Trauma Emerg Surg. 2013;39(6):591-8.

18. $D P G, R B, G d, G A, A N, R$ G: Prophylaxis of deep-vein thrombosis in fractures below the knee: a prospective randomised controlled trial. The Journal of bone and joint surgery British volume 2009, 91(3):388-394.

19. Zhang Lipeng ZZ. Analysis of the incidence and location of perioperative deep vein thrombosis in single fracture of lower extremity. J Trauma Surg. 2019;21:435-7

20. Park S-J, Kim C-K, Park Y-S, Moon Y-W, Lim S-J, Kim S-M. Incidence and factors predicting venous thromboembolism after surgical treatment of fractures below the hip. Journal of orthopaedic trauma. 2015;29.

21. Edmonds MJ, Crichton TJ, Runciman WB, Pradhan M: Evidence-based risk factors for postoperative deep vein thrombosis. 2015, 74(12):1082-1097.

22. Abelseth G, Buckley RE, Pineo GE, Hull R, Rose MS. Incidence of deep-vein thrombosis in patients with fractures of the lower extremity distal to the hip. Journal of orthopaedic trauma. 1996;10(4):230-5.

23. $W H ~ G, K I C, R M ~ J, E C, J P S$ : A prospective study of venous thromboembolism after major trauma. The New England journal of medicine 1994, 331(24):1601-1606.

24. Lee TH, Alonzo BJ, Differding J, Underwood SJ, Hamilton G, Kremenevskiy I, McNamara S, Schreiber MA. The effects of location and low-molecular-weight heparin administration on deep vein thrombosis outcomes in trauma patients. The journal of trauma and acute care surgery. 2013;74(2):476-81.

25. Batra S, Kurup H, Gul A, Andrew JG: Thromboprophylaxis following cast immobilisation for lower limb injuries_-survey of current practice in United Kingdom. 37(9):813-817.

26. Acute NCGC, Conditions C. Venous Thromboembolism: reducing the risk of venous thromboembolism (deep vein thrombosis and pulmonary embolism) in patients admitted to hospital. 2010;334(334):1053-4.
27. Yuwen P, Lv H, Chen W, Wang Y, Yu Y, Hao J, Liu S, Zhang T, Feng C, Guo J. Age-, gender- and Arbeitsgemeinschaft für Osteosynthesefragen typespecific clinical characters of adult tibial plateau fractures in eighty three hospitals in China. International Orthopaedics.

28. HEFLEY F. Effect of delayed admission to the hospital on the preoperatie prevalence of deep-vein thrombosis associated with fractures about the hip. Journal of Bone \& Joint Surgery American Volume. 1996;78.

29. S J. Ambulatory prevention of thrombosis in plaster immobilization of the lower extremity. Der Chirurg; Zeitschrift fur alle Gebiete der operativen Medizen. 1993;64(11):977-8.

30. Yi X, Zhu J, Wei M, Li J, Hu B. Risk factors of venous thrombosis in patients with ankle fractures. International Angiology. J Int Union of Angiology. 2014; 33(4):324-8.

31. Ginsberg JS, Brill-Edwards P, Panju A, Patel A, Ofosu F. Pre-operative plasma levels of thrombin-antithrombin III complexes correlate with the development of venous thrombosis after major hip or knee surgery. Thrombosis \& Haemostasis. 1995;74(2):602-5.

32. Bongard O, Wicky J, Peter R, Simonovska S, Vogel J-J, Moerloose Pd, Reber $\mathrm{G}$, Bounameaux H: D-dimer plasma measurement in patients undergoing major hip surgery: use in the prediction and diagnosis of postoperative proximal vein thrombosis. 74(5):0-493.

33. Dunn ID, Hui ACW, Triffitt PD, Crozier AEC, Mitchell VE. Plasma D-dimer as a marker for postoperative deep venous thrombosis: a study after total hip or knee arthroplasty. Thrombosis \& Haemostasis. 1994;72(5):663-5.

34. Wenjuan Z. Ying, Huai, Wei, Wang, Kaiyue, Xue, Lei, Chen: A retrospective cohort study on the risk factors of deep vein thrombosis (DVT) for patients with traumatic fracture at Honghui Hospital. BMJ Open. 2019 Mar 3;9(3): e024247.

35. Sally T, Hani T, Aurelie M, Ali T. Could sodium imbalances predispose to postoperative venous thromboembolism? An analysis of the NSQIP database. Thrombosis Journal. 2018;16(3):11.

36. Neuman MD, Silber JH, Elkassabany NM, Ludwig JM, Fleisher LA. Comparative effectiveness of regional versus general anesthesia for hip fracture surgery in adults. Anesthesiology. 2012;117(1):72-92.

37. Prins MH. A comparison of general anesthesia and regional anesthesia as a risk factor for deep vein thrombosis following hip surgery. A critical review. Thromb Haemost. 1990:64(04):497-500.

38. Hu S, Zhang Z-Y, Hua Y-Q, Li J, Cai Z-D: A comparison of regional and general anaesthesia for total replacement of the hip or knee: a META-ANAL YSIS. Journal of Bone \& Joint Surgery British Volume, 91b(7):935-942.

39. Jordan CDR, Walsh M, Tejwani N, Rosenberg A, Egol K. Spinal anesthesia mediates improved early function and pain relief following surgical repair of ankle fracture. JBJS. 2010;92:368-74.

\section{Publisher's Note}

Springer Nature remains neutral with regard to jurisdictional claims in published maps and institutional affiliations.

Ready to submit your research? Choose BMC and benefit from:

- fast, convenient online submission

- thorough peer review by experienced researchers in your field

- rapid publication on acceptance

- support for research data, including large and complex data types

- gold Open Access which fosters wider collaboration and increased citations

- maximum visibility for your research: over $100 \mathrm{M}$ website views per year

At BMC, research is always in progress.

Learn more biomedcentral.com/submission 